\title{
Fas-670A $>$ G polymorphism is not associated with an increased risk of acute myeloid leukemia development
}

\author{
YING HUANG ${ }^{1}$, DONGHONG DENG ${ }^{1},{\text { HONGYING } \text { LI }^{2} \text {, QIANG XIAO }}^{2}$, LULU HUANG $^{2}$, BING ZHANG $^{2}$, \\ FANGHUI $\mathrm{YE}^{2}$, BINGBING YE ${ }^{2}$, ZENGNAN MO ${ }^{3}$, XIAOBO YANG ${ }^{2,4}$ and ZHENFANG LIU ${ }^{1}$
}

\author{
${ }^{1}$ Department of Hematology, The First Affiliated Hospital of Guangxi Medical University; ${ }^{2}$ Center for Genomic and \\ Personalized Medicine, Guangxi Medical University; ${ }^{3}$ Institute of Urology and Nephrology, The First Affiliated Hospital of \\ Guangxi Medical University; ${ }^{4}$ Department of Occupational Health and Environmental Health, School of Public Health, \\ Guangxi Medical University, Nanning, Guangxi 530021, P.R. China
}

Received October 2, 2015; Accepted December 7, 2015

DOI: 10.3892/br.2015.564

\begin{abstract}
The association between the increased risk of acute myeloid leukemia (AML) and Fas promoter polymorphisms has been reported previously; however, the results are inconclusive. The present study performed one case-control study to investigate the association, and a total of 98 AML patients and 2,014 healthy controls were genotyped. The data showed that the distribution of Fas-670AA, GA and GG genotypes among the AML patients were not significantly different from those of the healthy controls, all $P>0.05$. Following this a sub-study was conducted to analyze individuals who neither smoked nor drank. The results demonstrated that there was still no significant association between the Fas-670 polymorphism and risk of AML development, all $\mathrm{P}>0.05$. Furthermore, in order to address a more accurate estimation of the association, a meta-analysis was conducted. Data were systematically collected from the Pubmed,EMBASE and the Wanfang Library. A total of 3 studies were included in this meta-analysis, which contained 1,144 AML cases and 3,806 controls. No significant association was detected between the Fas-670A $>$ G polymorphism and AML risk [GA+GG vs. AA: odds ratio (OR) 0.93; 95\% confidence interval (CI), 0.79-1.09; GG vs. AA: OR, 1.01; 95\% CI, 0.82-1.24; GA vs. AA: OR, 1.12; 95\% CI, 0.94-1.32; GG vs. AA+GA: OR, 0.94; 95\% CI, 0.79-1.12; G vs. A: OR, 1.01; 95\% CI, 0.91-1.12; all P>0.05). The analysis clearly indicated that there was no significant connection between the Fas-670A $>$ G polymorphism and the increased risk of AML.
\end{abstract}

Correspondence to: Dr Zhenfang Liu, Department of Hematology, The First Affiliated Hospital of Guangxi Medical University, 6 Shuangyong Road, Nanning, Guangxi 530021, P.R. China E-mail: liuliuzhenfang@126.com

Abbreviations: AML, acute myeloid leukemia; OR, odds ratio; CI, confidence interval

Key words: acute myeloid leukemia, Fas-670A $>$ G polymorphism, case-control study, genotyping, meta-analysis

\section{Introduction}

Fas is a type I transmembrane protein that can transform the apoptotic signal into susceptible target cells through the binding of the Fas ligand (FasL), belonging to the tumor necrosis factor/nerve growth factor family (1-3). The Fas/FasL signaling pathway is one of the well-characterised extrinsic pathways of apoptosis. While FasL combines with the death receptor Fas, Fas binds to the death domain (DD) of Fas-associated protein with DD (FADD) and recruits procaspase- 8 to construct the death-inducing signaling complex through the death effector domain of FADD. Apoptosis is a programmed process of normal cell death, which is regulated by genes and has a crucial role in maintaining physiological homeostasis (4). The out of control regulation of apoptosis could make a contribution to the pathogenesis of malignancies, such as ovarian cancer, breast cancer and neuroblastoma (5-7). Among haematological cancers, Fas-mediated apoptosis was presented in multiple myeloma, Burkitt's lymphoma and acute myeloid leukemia (AML) (8-11).

AML is one of the hematological malignancies caused by the malignant proliferation of myeloid protocells. In China, an incidence of 1.62/100,000 has been reported and the mortality of AML has been ranked as sixth place among the malignancies (12). The possible risk influence involved in AML includes occupational, environmental, lifestyle or genetic factors, although the specific etiology of the majority of leukemia remains to be elucidated (13-15). The results of previous studies demonstrated that the expression of Fas has been presented at cell surfaces of AML, suggesting that Fas-mediated apoptosis is likely to associate with the pathogenesis of AML $(16,17)$. Furthermore, a high-level expression of Fas was found in the myeloblasts and the lack of functional Fas signaling was reported to have a crucial role in several subtypes of AML (18). This evidence potentially provides the proof of the association between Fas-mediated apoptosis and the pathological mechanisms of AML.

Significant evidence has suggested that the Fas gene was regulated by a number of genetic components positioned in the 5 -upstream promoter region of the gene, particularly within the transcription factor binding sites (19). The Fas gene has been 
reported to be highly polymorphic from the dbSNP databases (http://www.ncbi.nlm.nih.gov/projects/SNP/). However, two potential functional polymorphisms have been most extensively studied, one involves an A-to-G substitution at the - 670 nucleotide position in the enhancer region (Fas-670A $>$ G, rs1800682) and the other a G-to-A allele mutation at the -1377 position within the silencer region, which alters the SP-1 transcription factor-binding site (Fas-1377G $>$ A, rs2234767) (20). They were reported to reduce Fas expression $(20,21)$. The composition of the Fas-670 polymorphism is the mutant homozygous genotype Fas-670G/G, heterozygous genotype Fas-670G/A and the wild homozygote Fas-670A/A. The statistical data of the wild homozygote among the healthy population ranged from 25.5 to $43.6 \%$, and the rate of mutant homozygote Fas-670G/G reached $12 \%$, whereas the frequency range of the heterozygous Fas-670A/G was $44.2-60.5 \%(22,23)$.

However, previous results regarding the association between the Fas gene polymorphism and risk of AML are controversial Only 2 studies discussed the linkage between the Fas gene polymorphism and the risk of AML. One of them confirmed that the mutations in the Fas promoter were associated with increasing the risk of AML in the Caucasian population, whereas the other verified that the variations of the Fas gene were not associated with the AML risk in Koreans $(21,24)$. In addition, other studies reported that there was no connection between the variation of Fas gene and malignancies $(25,26)$.

To explore the association between the mutation of the Fas gene and the risk of AML, a case-control study was conducted to test the frequency of the polymorphism at Fas-670A $>\mathrm{G}$ among patients with AML and the healthy population in China.

\section{Materials and methods}

Study subject. The present case-control study comprised 98 newly diagnosed AML patients and 2,014 healthy individuals. The classical morphological criteria of the French-American-British classification was used to establish diagnosis. Confirmed histopathology of the AML patients was consecutively recruited from The First Affiliated Hospital of Guangxi Medical University (Nanning, Guangxi, China) between 2011 and 2014. The individuals of the control group were randomly selected from the files of the Fangchenggang Area Male Health and Examination Survey (FAMHES), and they exhibited no history or diagnosis of carcinoma, as described previously (27). All the individuals were not related ethnicities and all the data were collected in southern China. A standardized questionnaire was issued regarding demographics and lifestyle, such as age, smoking and drinking, and the feedback was collected for analysis. The individuals who had smoked at least one cigarette per day lasting over half a year, either formerly or currently, were defined as smokers; others were non-smokers. The individuals who drank at least once a week lasting over half a year, either formerly or currently, were defined as drinkers; others were non-drinkers. The study was approved by the Ethics and Human Subject Committee of the First Affiliated Hospital of Guangxi Medical University, and all specimens were collected following informed consents.

DNA extraction and single nucleotide polymorphism (SNP) genotyping. Bone marrow $(2 \mathrm{ml})$ from each AML patient was drawn into Vacutainer tubes containing EDTA and stored at $-80^{\circ} \mathrm{C}$, and $2 \mathrm{ml}$ of peripheral blood from the control subjects was preserved using the same procedure. Subsequently, genomic DNA was isolated using the DNA isolation kit (Aidlab Biotechnologies, Beijing, China) and preserved at $-80^{\circ} \mathrm{C}$. SNP genotyping of AML was carried out using the SNaPshot Multiplex kit (Applied Biosystems; Thermo Fisher Scientific, Inc., Waltham, MA, USA) and the primers were shown as follows: Forward, ATAGCTGGGGCTATGCGA TTTG and reverse, GTTGGGGAGGTCTTGAAGGAGA. The genotyping information of the controls was extracted from the FAMHES database and the Omni 1 platform (Illumina, Inc., San Diego, CA, USA) was used for genotyping. The methods used were as previously described (28).

Identification of eligible studies. Studies on the association between the -670G/A polymorphism in the Fas gene and susceptibility of AML were selected by a comprehensive search (last study obtained was from August 2015) with English language only selected in the PubMed, EMBASE and Wanfang databases. The following search terms and their synonyms were used: 'Fas', '-670 G/A' or 'CD95', 'polymorphism' or 'mutation', and 'acute myeloid leukemia' or 'AML'. The cited references were also individually searched for the eligible studies.

Selection and exclusion criteria. The studies were identified according to the following criteria: i) The study must use a case-control design; ii) the study clarified the association between the $-670 \mathrm{G} / \mathrm{A}$ polymorphism in the Fas genes and the risk for AML; iii) presented adequate genotyping data (numbers of GG, GA and AA genotypes in the case and control groups, respectively) to estimate the odds ratio (OR) with the corresponding 95\% confidence interval (CI); iv) genotype distributions were in Hardy-Weinberg equilibrium (HWE) among controls ( $\mathrm{P}>0.05)$, and v) the study used human subjects. Studies meeting any of the following items should be excluded: i) Insufficient data; ii) the study used animal or cell subjects or subjects were children; iii) the study was based on other diseases, such as acute lymphoblastic leukaemia or myelodysplastic syndromes and the prognosis used medicine; and iv) duplicated studies.

Data extraction. Original data was extracted carefully from all the eligible studies by Ying Huang, according to the above selection and exclusion criteria to ensure the accuracy of the retrieved information, and the result was reviewed by a third investigator, Zhenfang Liu. Our research team extensively discussed and resolved the discrepancies. The following information was collected for each study: First author, year of publication, ethnicity, sample size of cases and controls, study period, and genotype distributions for cases and controls.

Statistical analysis. The differences of demographic variables between the cases and controls were derived using Pearson's $\chi^{2}$ test. The logistic regression was used to estimate the associations of polymorphisms and AML risk measured by ORs and $95 \%$ CIs. The pooled OR was estimated based on the individual ORs. It was evaluated for i) the dominant model (rare allele carriers versus common homozygous carriers); ii) recessive model (rare homozygous carriers versus common allele carriers); iii) codominant model (heterozygous versus 
Table I. Distribution of the characteristics of acute myeloid leukemia patients and the controls.

\begin{tabular}{|c|c|c|c|}
\hline Characteristics & Patients $(n=98)$ & Controls $(n=2,014)$ & P-value \\
\hline Median age, years (range) & $38.3(14-76)$ & $37.5(20-69)$ & 0.57 \\
\hline Non-smoker and non-drinker & $37.1(14-76)$ & $41.5(20-69)$ & 0.02 \\
\hline Male, n (\%) & $50(51.0)$ & $2,014(100.0)$ & $<0.01$ \\
\hline Non-smoker and non-drinker & $22(22.4)$ & $161(100.0)$ & $<0.01$ \\
\hline \multicolumn{4}{|l|}{ History of smoking, n (\%) } \\
\hline Smoker & $24(24.5)$ & $1,107(55.0)$ & $<0.01$ \\
\hline Non-smoker & $74(75.5)$ & $907(45.0)$ & \\
\hline \multicolumn{4}{|l|}{ History of drinking, n (\%) } \\
\hline Drinker & $17(17.3)$ & $1,721(85.5)$ & $<0.01$ \\
\hline Non-drinker & $81(82.7)$ & $293(14.5)$ & \\
\hline
\end{tabular}

Table II. Allele and genotype frequencies of Fas-670A $>$ G polymorphism among patients and controls and their association with acute myeloid leukemia risk following adjustment.

\begin{tabular}{|c|c|c|c|c|c|c|}
\hline Genotype & $\begin{array}{c}\text { Patients } \\
(\mathrm{n}=98), \mathrm{n}(\%)\end{array}$ & $\begin{array}{c}\text { Controls } \\
(\mathrm{n}=2,014), \mathrm{n}(\%)\end{array}$ & $\mathrm{OR}^{\mathrm{a}}(95 \% \mathrm{CI})$ & P-value & $\mathrm{OR}^{\mathrm{b}}(95 \% \mathrm{CI})$ & P-value \\
\hline $\mathrm{AA}$ & $17(17.3)$ & $433(21.5)$ & 1.00 & 0.58 & 1.00 & 0.79 \\
\hline GA & $53(54.1)$ & $1,013(50.3)$ & $1.34(0.77-2.35)$ & 0.30 & $1.21(0.66-2.21)$ & 0.55 \\
\hline GG & $28(28.6)$ & $568(28.2)$ & $1.27(0.69-2.35)$ & 0.45 & $1.25(0.64-2.45)$ & 0.51 \\
\hline $\mathrm{AA}+\mathrm{GA}$ & $81(82.7)$ & $1,581(78.5)$ & $1.32(0.77-2.25)$ & 0.31 & $1.22(0.69-2.18)$ & 0.50 \\
\hline
\end{tabular}

ORs and 95\% CIs were calculated by unconditional logistic regression adjusting for a age or ${ }^{\mathrm{b}}$ for drinking and smoking status. OR, odds ratio; CI, confidence interval.

common homozygous carriers and rare homozygous versus common homozygous), and iv) additive model (minor allele versus major allele) (29). To estimate the P-value among different studies, the $\chi^{2}$ based Q-test and $\mathrm{I}^{2}$ statistics [with values between 0 and $100 \%$, with higher values leading to greater heterogeneity (no heterogeneity, $\mathrm{I}^{2}, 0-25 \%$; moderate heterogeneity, $\mathrm{I}^{2}, 25-50 \%$; significant heterogeneity, $\mathrm{I}^{2}, 50-75 \%$; and extreme heterogeneity, $\left.\left.\mathrm{I}^{2}, 75-100 \%\right)\right]$ were used for checking the heterogeneity $(30,31)$. P $>0.05$ for the Q-test or $\mathrm{I}^{2}<50 \%$ demonstrates an absence of heterogeneity across studies. In this case, the fixed-effects model (the Mantel-Haenszel method) was used. Otherwise, the OR of each study was calculated by the random-effects model (the DerSimonian and Laird method). It assumes that the random-effects model indicates substantial diversity and evaluates the within-study sampling error and between-study variation (32). The assumption of the fixed-effects model is that all the studies are assessing the same underlying effect and consider only the within-study variance (33). Due to the analysis of 3 studies only, a subgroup analysis was not performed. Furthermore, a sensitivity analysis was employed to assess the stability of the results. The estimation of the potential publication bias was conducted using funnel plots and Begg's rank correlation test (34). HWE of the control groups was tested by the $\chi^{2}$ test for goodness of fit. All the P-values were two-sided. All the statistical analyses were performed with STATA 12.0 and SPSS 16.0 (SPSS, Inc., Chicago, IL, USA).

\section{Results}

Characteristics of AML patients and controls. The frequency of significance of the characteristics among cases and controls are presented in Table I. Cases and controls appeared to be adequately matched for age. The median age of cases was 38.3 years (range, 14-76 years) and that of the controls was 37.5 years (range, 20-69 years; $\mathrm{P}=0.57$ ). The gender rate of the controls was significantly different from that of cases as the controls were not collected to match with cases regarding gender $(\mathrm{P}<0.01)$. Similarly, the rate of smoking and drinking status was significantly different from that of the cases (all $\mathrm{P}<0.01$ ). In a subgroup analysis of non-smokers and non-drinkers, there were significant differences between the age and gender rates of the controls and that of the cases $(\mathrm{P}=0.02$ and $\mathrm{P}<0.01$, respectively). Two patients presented with an undifferentiated leukemia (M1: $n=2), 18$ with an immature granulocytic leukemia (M2: $n=18), 78$ with a monocytic leukemia (M4: n=51; M5: n=25; M6: n=2) and 2 were unknown.

Association between the Fas-670A $>G$ polymorphism and $A M L$ risk. Among the control group, genotype distributions were in HWE $(\mathrm{P}>0.05)$. Allele and genotype frequencies of the Fas-670A $>$ G polymorphism among the cases and controls and their association with AML risk are presented in Table II. The heterozygous GA genotype was the most frequent in patients with AML (54.1\%), whereas $28.6 \%$ exhibited the GG 
Table III. Allele and genotype frequencies of the Fas-670A $>\mathrm{G}$ polymorphism among non-smokers and non-drinkers and their association with acute myeloid leukemia risk following adjustment.

\begin{tabular}{lcccc}
\hline Genotype & $\begin{array}{c}\text { Patients } \\
(\mathrm{n}=68), \\
\mathrm{n}(\%)\end{array}$ & $\begin{array}{c}\text { Controls } \\
(\mathrm{n}=161), \\
\mathrm{n}(\%)\end{array}$ & OR $^{\mathrm{a}}(95 \% \mathrm{CI})$ & P-value \\
\hline $\mathrm{AA}$ & $11(16.2)$ & $38(23.6)$ & 1.00 & 0.46 \\
GA & $37(54.4)$ & $83(51.6)$ & $0.59(0.25-1.40)$ & 0.23 \\
GG & $20(29.4)$ & $40(24.8)$ & $0.91(0.46-1.77)$ & 0.77 \\
AA+GA & $57(83.8)$ & $123(76.4)$ & $1.31(0.51-3.39)$ & 0.58
\end{tabular}

${ }^{\mathrm{a} O R s}$ and $95 \%$ CIs were calculated by unconditional logistic regression adjusting for age. OR, odds ratio; CI, confidence interval.

genotype, and $17.3 \%$ were homozygous AA. There were no significant differences from those among the controls (50.3, 28.2 and $21.5 \%$, respectively). An unconditional logistic regression model was used to adjust for age. Compared to the wild homozygous AA genotype, the manifestation of variant alleles (heterozygous and variant homozygous genotypes) did not influence the risk of developing AML (GA vs. AA: OR, 1.34; 95\% CI, 0.77-2.35; $\mathrm{P}=0.30$; GG vs. AA: OR, 1.27; 95\% CI, 0.69-2.35; $\mathrm{P}=0.45 ; \mathrm{GA}+\mathrm{GG}$ vs. AA: OR, 1.32; $95 \% \mathrm{CI}, 0.77-2.25 ; \mathrm{P}=0.31)$. Similarly, there was no association between the Fas-670 polymorphism and the risk for AML following adjusting for age, smoking and drinking (Table II). Subsequently, a further subgroup analysis among non-smokers and non-drinkers was conducted. The Fas-670A $>$ G genetic variants did not show a statistically significant influence on the susceptibility of an individual to AML (GA vs. AA: OR, 0.59; 95\% CI, 0.25-1.40; P=0.23; GG vs. AA: OR, 0.91; 95\% CI, 0.46-1.77; $\mathrm{P}=0.77$; $\mathrm{GA}+\mathrm{GG}$ vs. AA: OR, 1.31; 95\% CI, 0.51-3.39; $\mathrm{P}=0.58$ ) (Table III).

Characteristics of the eligible studies. A total of 375 studies were retrieved through the initial search. Following screening by titles and abstracts, 348 studies were eliminated based on the inclusion and exclusion criteria (Fig. 1). Subsequent to browsing the full articles, 9 studies that used animals or cells as subjects, 2 that studied children and 9 that were regarding the prognosis were excluded. Five were excluded due to the deficiency of raw statistical data and they were not case-control studies. Finally, with the inclusion of the present experimental results, only 3 studies were included in this meta-analysis $(21,24)$. The characteristics of each study and the distributions of the Fas gene polymorphism among patients and controls are summarized in Table IV. Three separate studies consisted of 2 Asian population studies and 1 Caucasian population study. There were 3 case-control studies with 1,144 AML cases and 3,806 controls concerning the association between the Fas-670A/G polymorphism and the risk of AML. Two of these studies, including the present study, were hospital-based and one was population-based (21). Their genotype distributions among the controls were in agreement with HWE.

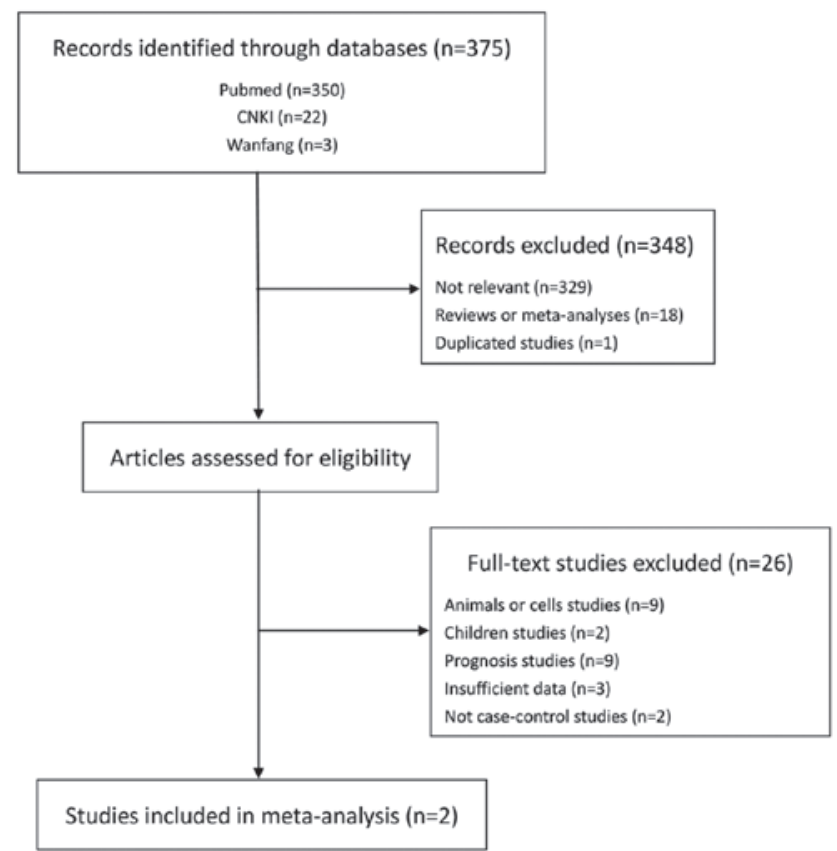

Figure 1. Flow diagram for the process of study screening.

Quantitative data analysis. No significant between-study heterogeneity was detected across studies, and thus the analyses were conducted using the fixed-effects models. Under the dominant model, the summary ORs and 95\% CIs for the Fas-670A/G polymorphism are shown in Table IV and its forest plot is shown in Fig. 2. The results illustrated that the Fas-670 polymorphism had no statistically evident association with the risk of AML (OR, 0.93; $95 \%$ CI, 0.79-1.09; $\mathrm{P}_{\text {heterogeneity }}=0.75 ; \mathrm{I}^{2}=0.0 \%$ ). Similar consequences were observed in other groups (G vs. A: OR, 1.01; 95\% CI, 0.91-1.12; $\mathrm{P}_{\text {heterogeneity }}=0.79 ; \mathrm{I}^{2}=0.0 \%$; GG vs. AA: $\mathrm{OR}, 1.01 ; 95 \%$ CI, 0.82-1.24; $\mathrm{P}_{\text {heterogeneity }}=0.70 ; \mathrm{I}^{2}=0.0 \%$; GA vs. AA: OR, 1.12; 95\% CI, 0.94-1.32; $\mathrm{P}_{\text {heterogeneity }}=0.81 ; \mathrm{I}^{2}=0.0 \%$; recessive model: OR, 0.94; 95\% CI, 0.79-1.12; $\mathrm{P}_{\text {heterogeneity }}=0.85$; $\mathrm{I}^{2}=0.0 \%$ ) (forest plot not shown). Owing to the deficiency of raw data, a subgroup analysis regarding non-smokers and non-drinkers could not be performed.

Sensitivity analyses. A sensitivity analysis was carried out by sequential removal of each individual eligible study to estimate the stability of the combined results and the source of the heterogeneity. The results indicated that the consequences were not materially altered by any single study (data not shown).

Publication bias. No clear asymmetry appeared to be shown in the Begg's funnel plot in all the genetic models, suggesting deficiency of publication bias (AA vs. $G A+G G$ : $P=0.30$ ). In addition, the Egger's test was conducted to provide statistical evidence for the lack of publication bias (AA vs. GA+GG: $\mathrm{P}=0.06$ ).

\section{Discussion}

The Fas gene is situated in chromosome 0q24.1, involving 9 exons, 8 introns and a promoter (35). Fas is the apoptotic 
Table IV. Characteristics of each study and the forest plot for the association of the Fas polymorphism with the risk of acute myeloid leukemia in the dominant model (AA vs. GA+GG).

\begin{tabular}{|c|c|c|c|c|c|c|c|c|c|c|}
\hline \multirow[b]{2}{*}{ First author, year } & \multirow[b]{2}{*}{ Country } & \multirow[b]{2}{*}{ Ethnicity } & \multirow[b]{2}{*}{ Case/control, $\mathrm{n}$} & \multicolumn{2}{|c|}{ Cases, n (\%) } & \multicolumn{2}{|c|}{ Controls, n (\%) } & \multirow[b]{2}{*}{ Weight, $\%$} & \multirow[b]{2}{*}{ OR $(95 \% \mathrm{CI})$} & \multirow[b]{2}{*}{ (Refs.) } \\
\hline & & & & AA & $\mathrm{AA}+\mathrm{GA}$ & AA & $\mathrm{AA}+\mathrm{GA}$ & & & \\
\hline Sibley, 2003 & UK & Caucasian & $454 / 934$ & $\begin{array}{c}129 \\
(28.4)\end{array}$ & $\begin{array}{c}357 \\
(78.6)\end{array}$ & $\begin{array}{c}280 \\
(30.0)\end{array}$ & $\begin{array}{r}729 \\
(78.1)\end{array}$ & 42.6 & $0.94(0.74-1.20)$ & (21) \\
\hline Kim, 2010 & Korea & Asian & $592 / 858$ & $\begin{array}{c}168 \\
(28.4)\end{array}$ & $\begin{array}{c}424 \\
(71.6)\end{array}$ & $\begin{array}{c}251 \\
(29.3)\end{array}$ & $\begin{array}{r}607 \\
(70.7)\end{array}$ & 46.8 & $0.96(0.76-1.21)$ & (24) \\
\hline Present study, 2015 & China & Asian & $98 / 2,014$ & $\begin{array}{c}17 \\
(17.4)\end{array}$ & $\begin{array}{c}81 \\
(82.7)\end{array}$ & $\begin{array}{c}433 \\
(21.5)\end{array}$ & $\begin{array}{l}1,581 \\
(78.5)\end{array}$ & 10.6 & $0.77(0.45-1.31)$ & \\
\hline Total & & & & 314 & & 370 & & 100.0 & $0.93(0.79-1.09)$ & \\
\hline
\end{tabular}

Heterogeneity: $\chi^{2}=0.08$ (d.f.=2), $\mathrm{P}=0.962, \mathrm{I}^{2}=0.0 \%$. Test for overall effect: $\mathrm{z}=0.69, \mathrm{P}=0.490$. OR, odds ratio; CI, confidence interval.

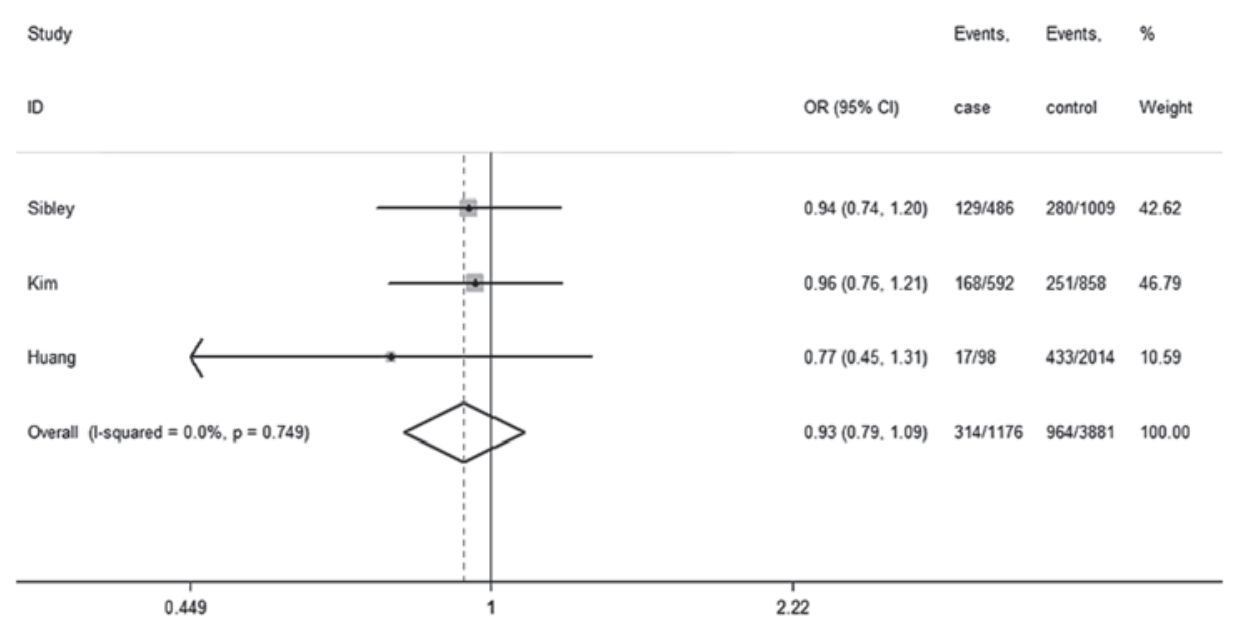

Figure 2. Forest plot for the association of the Fas-670A $>$ G polymorphism with the risk of acute myeloid leukemia in the dominant model (AA vs. GA+GG).

signal transmission reporter that is a type of transmembrane protein. When combined with its natural ligand FasL, it can initiate the apoptosis process by the death signal cascade (3). Thus, genetic polymorphisms in the Fas have an association with susceptibility to malignancies such as epithelial ovarian cancer or squamous cell carcinoma of the larynx and hypopharynx $(5,36)$. Among them, the polymorphism involving the $\mathrm{A} / \mathrm{G}$ alleles at the -670 nucleotide position in the promoter region (Fas-670A $>\mathrm{G}, \mathrm{rs} 1800682$ ) is one of the common mutations. It is located within the signal transducers and activators of transcription 1 (STAT1) binding element [interferon (IFN)- $\gamma$-activated sequence] and results from an ATCCG (G/A) AA substitution, which may have a functional gene regulation (20). In a new meta-analysis containing 52 case-control studies, there was no association between the Fas-670A $>$ G polymorphism and risk of cancers, including cervical cancer, gastric cancer, breast cancer and lung cancer. However, there was a significantly decreased risk in prostate cancers and melanoma for the $\mathrm{GG}+\mathrm{AG}$ vs. AA comparison model in the Fas-670A $>$ G polymorphism subgroup analysis, and a significantly increased risk was observed among those of the African population for the GG+GA vs. AA comparison model (37). This demonstrates that the Fas-670 polymorphism may have an association with certain types of cancer. Furthermore, recent results regarding the association between the Fas gene polymorphism and the risk of AML are controversial. Therefore, the present study conducted a case-control study and a meta-analysis to explore the association between the Fas-670A $>$ G polymorphism and the risk of AML.

However, the present results showed that the polymorphism at position -670 bp of the Fas gene had no association with the risk of developing AML. In accordance with the previous studies in the United Kingdom and Korea $(21,24)$, on the basis of analysis of 98 case patients and 2,014 matched normal controls, it was revealed that there was no significant connection between the Fas-670A $>$ G polymorphism and the risk of AML in the Chinese population. Similarly, in a subgroup analysis of non-smokers and non-drinkers, there were no significant differences between the Fas-670A $>\mathrm{G}$ polymorphism and the risk of AML. The present study, however, only included 98 cases and 2,014 controls, which was too small to confirm our proposed hypothesis. To solve this problem, a further meta-analysis was conducted. The meta-analysis, including 1,144 cases and 3,806 controls from 2 published case-control 
studies and one group of statistics from the present study, investigated the connection between a potentially functional mutation within the Fas promoter region and risk of AML. The results demonstrated that there was no evidence of the risk of AML associated with the Fas gene polymorphism at position $-670 \mathrm{bp}$. No significant association was observed with AML under any genetic model. A subgroup analysis regarding non-smokers and non-drinkers could not be performed owing to the absence of raw data. The deficiency of data for statistical analysis may cause a serious confounding bias. To minimize the likelihood bias, a detailed protocol was conducted prior to starting the study, and a meticulous search for eligible studies was carried out and used explicit methods for data extraction and statistical analysis. To the best of our knowledge, this is the first meta-analysis to investigate whether the Fas-670A $>\mathrm{G}$ genetic polymorphism was associated with the risk of AML. The result of a new study exploring the connection between Fas-670 polymorphism and susceptibility to leukemia was similar to the present study (38).

There are certain reasons that may explain the present result of the meta-analysis. In the first instance, the Fas-670A $>G$ polymorphism has no association with the risk of AML as the phosphorylation of transcription factor STAT1 is activated through the MEK/ERK pathway instead of the Fas/FasL pathway. The activated STAT1 has a crucial role in the process of drug-induced differentiation of AML cells $(39,40)$. Previous studies have indicated that Fas expression can be upregulated by IFN- $\gamma$ stimulation through STAT1 activation in monocytes isolated from -670AA genotype subjects, but not from subjects with the $-670 \mathrm{GG}$ genotype $(41,42)$. Sibley et al $(21)$ reported that there was a similar capacity in $-670 \mathrm{~A}$ and $-670 \mathrm{G}$ alleles to combine STAT1. However, STAT1 is a dasatinib off-target effect protein, which participates in the differentiation process and its phosphorylation is activated by the MEK/ERK pathway in AML (43). Therefore, we can assume that genetic mutations of the Fas/FasL pathway have no association with the risk of AML, although the Fas-670A $>$ G polymorphism is located within the STAT1 binding element. In addition, the Fas/FasL pathway may be obstructed by pathological immune cells in AML. Previous studies have reported that immune cells in malignancies have aberrant Fas and FasL genes, which induced downregulated Fas and upregulated FasL expressions (44-50). Target cells killed by cytotoxic T lymphocytes (CTLs) and natural killer cells are one of the mechanisms of apoptosis in the immune system, and the Fas/FasL pathway mediates the immune effect of CLTs (51-53). However, certain studies have revealed that the rate of regulatory T cells (Tregs) in peripheral blood and bone marrow of newly diagnosed AML patients was significantly higher than that in the healthy controls and it changed with their physical condition; for example, it decreased when the patients were in complete remission and it increased again when they relapsed (54-56). Zhou et al (57) revealed that Tregs could significantly suppress the proliferation and migration of CTLs. Therefore, Tregs in AML may inhibit Fas-induced apoptosis so that the Fas-670A $>$ G genetic polymorphism cannot reflect the development of AML.

According to the results of the present meta-analysis, we can presume a hypothesis that the Fas-670G allele substitution may serve to confer a molecular interaction to the action of the Fas-1377A allele. Although there is no significant association independently between the Fas-670A $>\mathrm{G}$ genetic polymorphism and the risk of AML, Sibley et al (21) found that $-670 \mathrm{~A}$, with the presence of $-1377 \mathrm{~A}$, increased the risk of AML significantly more than -670G. Look et al (58) reported the evidence for the transcriptional synergy between STAT1 and SP1, and this interaction may serve to confer an additional composition of specificity for transcription. They concluded that the recruitment of STAT1 to promotion may be conducted by SP1, and SP1 may serve as a better linkage of STAT1 action to the basal transcription complex. Considering the above evidence, we can presume that the guanine substitution at the $-670 \mathrm{bp}$ position in the Fas gene may serve to confer a molecular interaction to the action of Fas-1377A allele; however, further studies are required to detect the association between the downstream protein of the Fas- $670 \mathrm{~A}>\mathrm{G}$ polymorphism and AML risk.

However, the present study has certain limitations. Firstly, it has been reported that there are certain copy number variations in the Fas gene sequence from the dbVar database (http://www. ncbi.nlm.nih.gov/dbvar), which could affect the results of SNP regarding the association between gene polymorphism and the disease. Secondly, there are mismatches between the patients and the control subjects with regards to the rate of gender and history of drinking alcohol and smoking. In the meta-analysis, further subgroup analysis by age, gender and different populations could not be conducted due to the insufficient detailed information. Furthermore, it has been reported that a small number of studies could affect the results and more relevant studies are required to draw a more accurate conclusion. Finally, a potential English language bias may exist as English literature only was selected, and there may be differences between English language literature and others. Therefore, whether a genetic polymorphism exists in the incidence of AML between regions could not be concluded.

In conclusion, the present study suggested that there was no significant association independently between the Fas-670A $>$ G polymorphism and the risk of AML. To reach a definitive conclusion, more well-designed studies with larger samples are required to identify an association between this polymorphism and the risk of AML.

\section{Acknowledgements}

The present study was supported by grants from the Guangxi Natural Science Foundation (nos. 2010GXNSFA013181 and 2010GXNSFB013064), Guangxi Science Fund for Distinguished Young Scholars (no. 2012GXNSFFA060009), and National Natural Science Foundation of China (nos. 81160072 and 81560028).

\section{References}

1. Nagata S: Apoptosis regulated by a death factor and its receptor: Fas ligand and Fas. Philos Trans R Soc Lond B Biol Sci 345: 281-287, 1994.

2. Nagata S: Apoptosis by death factor. Cell 88: 355-365, 1997.

3. Itoh N, Yonehara S, Ishii A, Yonehara M, Mizushima S, Sameshima M, Hase A, Seto Y and Nagata S: The polypeptide encoded by the cDNA for human cell surface antigen Fas can mediate apoptosis. Cell 66: 233-243, 1991.

4. Zornig M, Hueber A, Baum W and Evan G: Apoptosis regulators and their role in tumorigenesis. Biochim Biophys Acta 1551: F1-F37, 2001. 
5. Li Y, Hao YL, Kang S, Zhou RM, Wang N and Qi BL: Genetic polymorphisms in the Fas and FasL genes are associated with epithelial ovarian cancer risk and clinical outcomes. Gynecol Oncol 128: 584-589, 2013.

6. Wang W, Zheng Z, Yu W, Lin H, Cui B and Cao F: Polymorphisms of the FAS and FASL genes and risk of breast cancer. Oncol Lett 3: 625-628, 2012.

7. Han W, Zhou Y, Zhong R, Wu C, Song R, Liu L, Zou L, Qiao Y, Zhai K, Chang J, et al: Functional polymorphisms in FAS/FASL system increase the risk of neuroblastoma in Chinese population. PloS One 8: e71656, 2013.

8. Westendorf JJ, Lammert JM and Jelinek DF: Expression and function of Fas (APO-1/CD95) in patient myeloma cells and myeloma cell lines. Blood 85: 3566-3576, 1995.

9. Shima Y, Nishimoto N, Ogata A, Fujii Y, Yoshizaki K and Kishimoto T: Myeloma cells express Fas antigen/APO-1 (CD95) but only some are sensitive to anti-Fas antibody resulting in apoptosis. Blood 85: 757-764, 1995.

10. Gutierrez MI, Cherney B, Hussain A, Mostowski H, Tosato G Magrath I and Bhatia K: Bax is frequently compromised in Burkitt's lymphomas with irreversible resistance to Fas-induced apoptosis. Cancer Res 59: 696-703, 1999.

11. Pordzik S, Petrovici K, Schmid C, Kroell T, Schweiger C, Köhne $\mathrm{CH}$ and Schmetzer $\mathrm{H}$ : Expression and prognostic value of FAS receptor/FAS ligand and TrailR1/TrailR2 in acute myeloid leukemia. Hematology 16: 341-350, 2011.

12. Chongli Y and Xiaobo Z: Anemia CESGoLaA: Incidence Survey of Leukemia in China in 1986. Chinese Journal of Hematology 10: 618-621, 1986.

13. Kasim K, Levallois P, Abdous B, Auger P and Johnson KC: Lifestyle factors and the risk of adult leukemia in Canada. Cancer Causes Control 16: 489-500, 2005.

14. Wong O, Harris F, Yiying W and Hua F: A hospital-based case-control study of acute myeloid leukemia in Shanghai: Analysis of personal characteristics, lifestyle and environmental risk factors by subtypes of the WHO classification. Regul Toxicol Pharmacol 55: 340-352, 2009.

15. Filippini T, Heck JE, Malagoli C, Del Giovane C and Vinceti M: A review and meta-analysis of outdoor air pollution and risk of childhood leukemia. J Environ Sci Health C Environ Carcinog Ecotoxicol Rev 33: 36-66, 2015.

16. Min YJ, Lee JH, Choi SJ, Chi HS, Lee JS, Kim WK and Lee KH: Prognostic significance of Fas (CD95) and TRAIL receptors (DR4/DR5) expression in acute myelogenous leukemia. Leuk Res 28: 359-365, 2004.

17. Iijima N, Miyamura K, Itou T, Tanimoto M, Sobue R and Saito H: Functional expression of Fas (CD95) in acute myeloid leukemia cells in the context of CD34 and CD38 expression: Possible correlation with sensitivity to chemotherapy. Blood 90 : 4901-4909, 1997

18. Komada Y, Zhou YW, Zhang XL, Xue HL, Sakai H, Tanaka S, Sakatoku H and Sakurai M: Fas receptor (CD95)-mediated apoptosis is induced in leukemic cells entering G1B compartment of the cell cycle. Blood 86: 3848-3860,1995.

19. Nunobiki O, Ueda M, Toji E, Yamamoto M, Akashi K, Sato N, Izuma S, Torii K, Tanaka I, Okamoto Y and Noda S: Genetic polymorphism of cancer susceptibility genes and HPV infection in cervical carcinogenesis. Patholog Res Int 2011: 364069, 2011.

20. Huang QR, Morris D and Manolios N: Identification and characterization of polymorphisms in the promoter region of the human Apo-1/Fas (CD95) gene. Mol Immunol 34: 577-582, 1997.

21. Sibley K, Rollinson S, Allan JM, Smith AG, Law GR, Roddam PL, Skibola CF, Smith MT and Morgan GJ: Functional FAS promoter polymorphisms are associated with increased risk of acute myeloid leukemia. Cancer Res 63: 4327-4330, 2003.

22. Sun T, Zhou Y, Li H, Han X, Shi Y, Wang L, Miao X, Tan W, Zhao D, Zhang X, et al: FASL-844C polymorphism is associated with increased activation-induced $\mathrm{T}$ cell death and risk of cervical cancer. J Exp Med 202: 967-974, 2005.

23. Kordi Tamandani DM, Sobti RC and Shekari M: Association of Fas-670 gene polymorphism with risk of cervical cancer in North Indian population. Clin Exp Obstet Gynecol 35: 183-186, 2008.

24. Kim HJ, Jin XM, Kim HN, Lee IK, Park KS, Park MR, Jo DY, Won JH, Kwak JY, Kim HJ, et al: Fas and FasL polymorphisms are not associated with acute myeloid leukemia risk in Koreans. DNA Cell Biol 29: 619-624, 2010.

25. Lai HC, Lin WY, Lin YW, Chang CC, Yu MH, Chen CC and Chu TY: Genetic polymorphisms of FAS and FASL (CD95/CD95L) genes in cervical carcinogenesis: An analysis of haplotype and gene-gene interaction. Gynecol Oncol 99: 113-118, 2005.
26. Park SH, Choi JE, Kim EJ, Jang JS, Lee WK, Cha SI, Kim CH, Kam S, Kim DS, Park RW, et al: Polymorphisms in the FAS and FASL genes and risk of lung cancer in a Korean population. Lung Cancer 54: 303-308, 2006.

27. Tan A, Gao Y, Yang X, Zhang H, Qin X, Mo L, Peng T, Xia N and Mo Z: Low serum osteocalcin level is a potential marker for metabolic syndrome: Results from a Chinese male population survey. Metabolism 60: 1186-1192, 2011.

28. Yang X, Sun J, Gao Y, Tan A, Zhang H, Hu Y, Feng J, Qin X, Tao S, Chen Z, et al: Genome-wide association study for serum complement $\mathrm{C} 3$ and $\mathrm{C} 4$ levels in healthy Chinese subjects. PLoS Genet 8: e1002916, 2012.

29. Tian J, Pan F, Li J, Ma Y, Cen H, Pan HF, Pan YY and Ye DQ: Association between the FAS/FASL polymorphisms and gastric cancer risk: A meta-analysis. Asian Pac J Cancer Prev 13: 945-951, 2012

30. Higgins JP, Thompson SG, Deeks JJ and Altman DG: Measuring inconsistency in meta-analyses. BMJ 327: 557-560, 2003.

31. William GC: The combination of estimates from different experiments. Biometrics 10: 101-129, 1954.

32. DerSimonian R and Laird N: Meta-analysis in clinical trials. Control Clin Trials 7: 177-188, 1986.

33. Mantel $\mathrm{N}$ and Haenszel W: Statistical aspects of the analysis of data from retrospective studies of disease. J Natl Cancer Inst 22: 719-748, 1959.

34. Begg CB and Mazumdar M: Operating characteristics of a rank correlation test for publication bias. Biometrics 50: 1088-1101, 1994.

35. Behrmann I, Walczak H and Krammer PH: Structure of the human APO-1 gene. Eur J Immunol 24: 3057-3062, 1994

36. Wang J, Gao J, Li Y, Zhao X, Gao W, Peng L, Yan D, Liu L, Li D, Wei L, et al: Functional polymorphisms in FAS and FASL contribute to risk of squamous cell carcinoma of the larynx and hypopharynx in a Chinese population. Gene 524: 193-196, 2013.

37. Xu Y, He B, Li R, Pan Y, Gao T, Deng Q, Sun H, Song G and Wang S: Association of the polymorphisms in the Fas/FasL promoter regions with cancer susceptibility: A systematic review and meta-analysis of 52 studies. PloS One 9: e90090, 2014.

38. Chen Y, He Y, Lu X, Zeng Z, Tang C, Xue T and Li Y: Association between Fas/FasL polymorphism and susceptibility to leukemia: A meta-analysis. Int J Clin Exp Med 8: 3817-3824, 2015

39. Gianni M, Terao M, Fortino I, LiCalzi M, Viggiano V, Barbui T, Rambaldi A and Garattini E: Statl is induced and activated by all-trans retinoic acid in acute promyelocytic leukemia cells Blood 89: 1001-1012, 1997.

40. Battle TE and Frank DA: STAT1 mediates differentiation of chronic lymphocytic leukemia cells in response to Bryostatin 1. Blood 102: 3016-3024, 2003

41. Kanemitsu S, Ihara K, Saifddin A, Otsuka T, Takeuchi T, Nagayama J, Kuwano M and Hara T: A functional polymorphism in fas (CD95/APO-1) gene promoter associated with systemic lupus erythematosus. J Rheumatol 29: 1183-1188, 2002.

42. Farre L, Bittencourt AL, Silva-Santos G, Almeida A, Silva AC, Decanine D, Soares GM, Alcantara LC Jr, Van Dooren S, Galvão-Castro B, et al: Fas 670 promoter polymorphism is associated to susceptibility, clinical presentation and survival in adult T cell leukemia. J Leukoc Biol 83: 220-222, 2008.

43. Fang Y, Zhong L, Lin M, Zhou X, Jing H, Ying M, Luo P, Yang B and He Q: MEK/ERK dependent activation of STAT1 mediates dasatinib-induced differentiation of acute myeloid leukemia. PloS One 8: e66915, 2013.

44. Wu J, Wilson J, He J, Xiang L, Schur PH and Mountz JD: Fas ligand mutation in a patient with systemic lupus erythematosus and lymphoproliferative disease. J Clin Invest 98: 1107-1113, 1996.

45. Wang J, Zheng L, Lobito A, Chan FK, Dale J, Sneller M, Yao X, Puck JM, Straus SE and Lenardo MJ: Inherited human caspase 10 mutations underlie defective lymphocyte and dendritic cell apoptosis in autoimmune lymphoproliferative syndrome type II. Cell 98: 47-58, 1999

46. Chun HJ, Zheng L, Ahmad M, Wang J, Speirs CK, Siegel RM, Dale JK, Puck J, Davis J, Hall CG, et al: Pleiotropic defects in lymphocyte activation caused by caspase- 8 mutations lead to human immunodeficiency. Nature 419: 395-399, 2002.

47. Kennedy NJ, Kataoka T, Tschopp J and Budd RC: Caspase activation is required for T cell proliferation. J Exp Med 190: 1891-1896, 1999.

48. Alam A, Cohen LY, Aouad S and Sékaly RP: Early activation of caspases during $\mathrm{T}$ lymphocyte stimulation results in selective substrate cleavage in nonapoptotic cells. J Exp Med 190: 1879-1890, 1999. 
49. Su H, Bidère N, Zheng L, Cubre A, Sakai K, Dale J, Salmena L, Hakem R, Straus S and Lenardo M: Requirement for caspase-8 in NF-kappaB activation by antigen receptor. Science 307: 1465-1468, 2005.

50. Newton K, Harris AW, Bath ML, Smith KG and Strasser A: A dominant interfering mutant of FADD/MORT1 enhances deletion of autoreactive thymocytes and inhibits proliferation of mature T lymphocytes. EMBO J 17: 706-718, 1998.

51. Rouvier E, Luciani MF and Golstein P: Fas involvement in $\mathrm{Ca}(2+)$-independent $\mathrm{T}$ cell-mediated cytotoxicity. J Exp Med 177: 195-200, 1993.

52. Suda T and Nagata S: Purification and characterization of the Fas-ligand that induces apoptosis. J Exp Med 179: 873-879, 1994.

53. Kagi D, Vignaux F, Ledermann B, Bürki K, Depraetere V, Nagata S, Hengartner $\mathrm{H}$ and Golstein P: Fas and perforin pathways as major mechanisms of T cell-mediated cytotoxicity. Science 265: 528-530, 1994.
54. Szczepanski MJ, Szajnik M, Czystowska M, Mandapathil M, Strauss L, Welsh A, Foon KA, Whiteside TL and Boyiadzis M: Increased frequency and suppression by regulatory $\mathrm{T}$ cells in patients with acute myelogenous leukemia. Clin Cancer Res 15: 3325-3332, 2009.

55. Ustun C, Miller JS, Munn DH, Weisdorf DJ and Blazar BR: Regulatory $\mathrm{T}$ cells in acute myelogenous leukemia: Is it time for immunomodulation? Blood 118: 5084-5095, 2011.

56. Yang $\mathrm{W}$ and $\mathrm{Xu}$ Y: Clinical significance of Treg cell frequency in acute myeloid leukemia. Int J Hematol 98: 558-562, 2013

57. Zhou Q, Munger ME, Highfill SL, Tolar J, Weigel BJ, Riddle M, Sharpe AH, Vallera DA, Azuma M, Levine BL, et al: Program death-1 signaling and regulatory $\mathrm{T}$ cells collaborate to resist the function of adoptively transferred cytotoxic $\mathrm{T}$ lymphocytes in advanced acute myeloid leukemia. Blood 116: 2484-2493, 2010.

58. Look DC, Pelletier MR, Tidwell RM, Roswit WT and Holtzman MJ: Stat1 depends on transcriptional synergy with Sp1. J Biol Chem 270: 30264-30267, 1995. 